- into the planet's atmosphere within a few months. "Why do they disappear so quickly?" asks John Moores, a planetary scientist at York University in Toronto, Canada. "There's some piece of the puzzle we are missing."

Researchers are looking for answers in the gap between Curiosity, which sniffs for methane 1 metre above Mars's surface, and the TGO, which takes its best measurements at least 5 kilometres above the planet. The scientists are trying to determine how the gas could be destroyed relatively close to Mars's surface.

One possibility is that methane seeping out of the ground is removed by a low-altitude chemical reaction - perhaps involving dust - before it can drift higher into the air, says Michael Mumma, a planetary scientist at NASA's Goddard Space Flight Center in Greenbelt, Maryland. A team based at Aarhus University in
Denmark, which has studied how dust particles could deplete Martian methane, will describe its ideas on 11 April at the European Geosciences Union meeting in Vienna.

The work is timely because a giant dust storm spread across Mars in June 2018. It obscured the atmosphere and temporarily forced the TGO to focus its methane search on high elevations and latitudes.

Some scientists are sceptical that the TGO will ultimately find the gas. "I've never seen a convincing detection of indigenous methane on Mars, and I don't believe I ever will," says Kevin Zahnle, a planetary scientist at NASA's Ames Research Center in Moffett Field, California, who has argued that reports of Martian methane are observational errors.

But Oehler says that methane probably wafts out of geologically active regions on Mars, such as those riddled with faults. With the only ground measurements coming from Curiosity, scientists simply haven't had the chance to observe how the gas might be seeping from different parts of the surface, or how methane might be destroyed as it drifts upward.

The TGO will continue to monitor Mars's atmosphere through at least 2022. So far, it has observed only a fraction of a Martian year, which lasts nearly two Earth years. Hints of methane might yet emerge as the seasons pass. "One thing about Mars is it's never boring," says Oehler. .

\footnotetext{
1. Korablev, O. et al. Nature http://doi.org/10.1038/ s41586-019-1096-4 (2019).

2. Mumma, M. J. et al. Science 323, 1041-1045 (2009).

3. Webster, C. R. et al. Science 360, 1093-1096 (2018).

4. Giuranna, M. et al. Nature Geosci. http://doi. org/10.1038/s41561-019-0331-9 (2019).
}

\title{
Cancer geneticists tackle ethnic bias in studies
}

\section{Efforts are under way to fill long-standing gaps in genomic data from minority groups.}

\section{BY HEIDI LEDFORD, ATLANTA, GEORGIA}

$\mathrm{W}$ hen Bárbara Segarra-Vázquez’s breast cancer came roaring back last summer after a 13-year hiatus, her physicians recommended surgery and a genetic test to determine whether chemotherapy was warranted. The test results suggested that she could forgo the drugs, and she did. But a nagging doubt remains.

"They said, 'You don't need chemo.' But do I, or do I not?" says Segarra-Vázquez, dean of the School of Health Professions at the University of Puerto Rico in San Juan, who is Latina. "I don't know, because they didn't test people like me. The validation of that test was done in white Europeans."

Her story illustrates a long-standing bias in cancer research: most studies and genetic databases are populated mainly by data from people of European descent. This knowledge gap exacerbates disparities in cancer incidence and outcomes around the world. In the United States, for example, African American men are about twice as likely as white men to die of prostate cancer.

But researchers who study these inequities say they are encouraged by renewed interest in closing the data gap from their colleagues and funders, including the US government. The issue was unusually prominent at the annual meeting of the American Association

for Cancer Research (AACR) this month in Atlanta, Georgia - one of the world's biggest gatherings of cancer researchers.

"It's a historical year for us working in cancer health disparities," says Laura Fejerman, a geneticist at the University of California, San Francisco, who studies breast cancer in Latina women. "We've been trying to show researchers who don't work on health disparities that this is a really important issue."

Differences in cancer risk and survival are thought to be caused by a complex mix of social, economic and genetic factors. The criteria used to select participants for clinical trials are often

\section{"We still have a long way to go."}

unintentionally biased against minority ethnic groups - for example, by excluding people with certain disorders that are more common in such populations. And members of these groups are sometimes distrustful of medical researchers, a legacy of past discrimination and studies conducted without adequate consent.

Then there is the simple matter of numbers: the rarer a cancer, the harder it is to enrol enough study participants from a minority population to gather statistically meaningful data. A crop of large studies is attempting to address this problem, Fejerman says. They include an effort that the AACR launched last year to sequence the genomes of tumours from

\section{2,020 African Americans by 2020.}

Another project, announced last July and about to start recruiting participants, aims to enrol 10,000 African American men recently diagnosed with prostate cancer. The US\$26.5million effort is funded by the US National Institutes of Health and the Prostate Cancer Foundation, a charity in Santa Monica, California. Led by genetic epidemiologist Christopher Haiman of the University of Southern California in Los Angeles, it will examine not only biological features of participants' cancers, but also characteristics of their neighbourhoods and the social stressors - such as discrimination - they have experienced.

"People tend to think that the molecular features of a tumour are everything," says Jennifer Doherty, a cancer epidemiologist at the Huntsman Cancer Institute at the University of Utah in Salt Lake City. "But then we don't remember that the tumour exists within a human being."

\section{A CLOSER LOOK}

How genomic data is collected and labelled is also becoming more nuanced, as researchers re-examine the broad ethnic categories they have long used. The term 'Asian' encompasses dozens of countries with disparate lifestyles and genetic backgrounds. Similarly, 'African American' is used to refer to US citizens of African descent, regardless of which region of 
